\title{
Innovation Research on the Student Management in University Based on Cross-cultural Management
}

\author{
Duan Kaige $^{1}$ \\ ${ }^{1}$ College of Foreign Studies in Jinan University Jinan \\ University, Guangzhou, China.
}

\author{
Fu Yonggang ${ }^{2}$ \\ ${ }^{2}$ School of Translation Studies, Jinan University
}

\begin{abstract}
Internationalization of Higher Education gives a challenge to College Student Management. The diversity of students' regions requires innovative management of college students. The thesis regards Cross-cultural Management Theory as a great perspective and combines it with the management of the college students, so that we can explore new thoughts from the aspects of the body and the whole structure.
\end{abstract}

Keywords: Colleges and Universities; College Student Management; Cross-cultural Management; Innovative Management

\section{INTRODUCTION}

The main line of Chinese College Management is ideological and political education which is founded on holistic education and student-centered education. This pattern focuses on students' affectional guidance and the formation of value judgments. However, currently this traditional College Student Management pattern is seriously challenged by the internationalization of higher education. In $21^{\text {st }}$ century, as the internationalization of higher education goes deepen, the growing diversity of students' backgrounds brings about the complexity of the management for the explicit and implicit cultural conflicts. In order to deal with this issue, Cross-cultural Management is indispensable.

Therefore, how to deal with cultural differences in student management and promote students' development has become the important task of College Students' Management innovation. This thesis is trying to introduce Cross-cultural Theory into Chinese College Student Management, and combine the characteristics of original Chinese ways of management and the needs of student development. And finally approach to the preliminary exploration of new ideas for cross - cultural management of students.

\section{Cross-cultural Management Theory}

Here is going to introduce the research background of this paper and reviewed the domestic and international research results. The causes of Cross-cultural Management research are cultural differences and cultural conflicts. Cultural differences exist objectively. Different countries develop different historical cultures, conventional cultures, regional cultures, and religious cultures, etc. And cultural differences are shown by individuals' values, behaviors, and religious beliefs, as well as customs and habits. In addition, these differences will not disappear or weaken while accompanied with the globalization of economy and education. Culture shock refers to the conflicts of values and behaviors of individuals representing different cultural groups. Comparing with cultural difference, culture conflict is subjective. On account of its generation is related to the sense of culture, the understanding of culture and cultural prejudice. That is to say, cultural conflict can be avoided and accordingly cultural conflict is a breakthrough of Cross-cultural Management research.

Integrating the studies, I think intercultural communications means a cross into the threshold of the realm of another culture and use their values as standards to think and behave. Therefore, Cross-culture Management requires governing bodies span their own cultural limitations and sink into foreign cultures for successful organization, coordination and control. Nowadays, the main research results include Kluckhohn and Fred Strodtbeck' s Six Orientations Theory ( 1961), Hofstede's Theory of Cultural Dimensions (1980, 1991) and Model of National Cultural Differences of Trompenaars (1993, 1998). Most researches are from the viewpoint of cultural dimension; hence they are concentrated on dimensions and methods distinguishing the national or ethnic cultural differences.

\section{Organic Combination of Cross-cultural Management and College Student Management}

\subsection{Introducing Cross-cultural Management to College Student Management}

Domestic research starts relatively late on intercultural management, especially intercultural management in education has received less serious attention. So far, Tao Ling has made a preliminary study on the macro-level of cross-culture college education management while Zhang Yutang has achieved the initial success on the middle- 
cosmic level of it. With regard to microcosmic aspect, it is still an entirely new level for scholars. And introducing the concept of cross-cultural management and using its essential principles as guidance of education management leads to the foundation of Chinese Cross-cultural Student Management.

- Management subject is the college counselors (managers) who can strive to be the guiding function of cultural conflicts revolution.

- Management object is the college students of many different ages and coming from a wide variety of social culture and economic back-grounds.

- Management Objectives are not only aimed at managing conflicts but for comment development.

\subsection{Setting Student Multicultural Models by Using Cultural Dimension Theory}

Hofstede attributed the causes of cultural differences into 5 dimensions including Individualism verse Collectivism, Power Distance, Uncertainty Avoidance, Masculine and Femininity, and Long-Term Orientation verse short-term orientation by empirical researches. And then each dimension is quantified into specific data. According to the scores which nations get from the 5 dimensions, the cultural differences among these countries can be analyzed.

First of all, for Individualism verse Collectivism dimension, the data of Asian countries are significantly different from Western countries', such as the United States and the United Kingdom get 91 and 89 respectively while China and Korea are 20 and 18 respectively. It indicates that Asia advocate collectivism values simply meaning Asians would like to associate individual benefits with organizational interests and emphasize personal loyalty to the Organization. However, individualistic values of Western countries focus on personality development.

Secondly, as for Power Distance dimension, the distance in South-East Asian countries (regions) is located at the top of the list, such as the datum of Singapore is 74, the datum of Philippines is 94, while that of Hong Kong is 68. Strict hierarchy exists in these countries and regions by presenting that the bosses have most absolute authority. Moreover they emphasize obedience and value the qualifications. While the Power Distance in Western countries is generally not that powerful. The figure of the United States is 40 and that of United Kingdom is 35. According to these figures, they do not zeal for the power relatively, but cherish the value of equality and admire the abilities of individuals.

Thirdly, in relation to Uncertainty Avoidance, there are no much significant differences between Eastern and Western countries.

Fourthly, concerning Masculine and Femininity, Japan gets the highest score, 95, far further than in most other countries. Manifesting that Japan is a country with sexually discrimination of orientation of man and admiring personal success.
Finally, in regard to Long-Term Orientation verse shortterm orientation. In this dimension, without suspicion, China takes 118, the highest score. While the United Kingdom and the United States scored lowest, 25 and 29 respectively. The result leads to the pragmatic orientation of Chinese who concerns about future instead of the shortterm interests. And Chinese also concern about saving and accumulation, while Britain and the United States or other Western countries lay stress on immediate benefits, quick efficiency and time- consuming.

\subsection{Cultural Analysis and Cultural Understanding}

Both the Iceberg Model and the Onion Model illustrate the implicitness and explicitness of culture vividly. If students managers want to promote the job of student development and education functionally, they should move their eyes off students external behaviors but to their inside thoughts. And they should pay attention to students' cultural background and make a rational analysis. Therefore, the cultivation of cross-cultural understanding requires the sufficient comprehension of native and foreign cultures. So the continuous learning of the different cultures is the prerequisite of cultural education.

\subsection{The Establishment of Cultural Symbiosis in According to Cultural Features of College Students}

Currently the treatment modes of cross-cultural conflicts are mainly came up with by Nancy $\cdot \mathbf{J} \cdot$ Adler who is the most famous Canadian international cultural organizational manager. In her perspective, there are three choices including overriding, compromising and integrating. In the meantime, some scholars hold the transplantation model comprising suppression, evasion, as well as acceptance and fossilization translation. The final results will be the aggravation of conflicts, delitescent crisis, stability and mutual exclusion respectively.

I think integration and conflict should not be the absolute forms. There are other options, such as the cultural symbiosis.

From the perspective of the development of culture, it is impossible to completely eliminate the conflicts between different cultures, either to achieve a real integration.

In light of the above mentioned reasons, I think cultural symbiosis not only can be a result of culture conflicts but also a treatment mode. And it is the best choice for the preservation and generation of world culture. In this context, an Answer to globalization should be enhancing Culture Self-consciousness. As Mr. Fei Xiaotong advocated that 'Beautify one's own beauty, beautify other's beautify, beautify all the beauty, then comes to the Great Harmony of the World'.

To sum up, the organic combination of Management Theory and Student College Management requires managers to have a sense of identifying and understanding of cultures, and to have the ability to choose the right mode dealing with the conflicts. Then managers also need to 
master certain intercultural skills, and they should be good at finding the common ground of different cultures.

\section{Developing New Ideas of Cross-cultural Management}

\subsection{Developing Cross-cultural Aware- ness in the Student Management}

Intercultural management is not only a management theory and method; it is also management awareness. The functions of it lie in the guidance, constraint, and regularization of social behaviors. And it can provide the direction with the whole organization. Right management philosophy can be the precursor to promote the advancing of management. Given the diversity of college students in China, in my opinion, if we want to develop awareness of cross-cultural management, our managers should update and remodel management concept instead of using the old ones. That means manages need to reposition themselves and management object in the view of cross-culture frequently. They also should keep firmly in mind with the basic idea that cultural differences are everywhere.

\subsection{Professional Development of Manages}

First of all, improving knowledge structure of governing body is very important.

Governing bodies have been playing a more and more essential role. And because their final goal is imparting knowledge and educating students, so they should have a basic knowledge on the study of pedagogy and psychology, and even on behavioral science and cross-culture management.

Secondly, training managers with cross-cultural sensitivity will be helpful.

There is various way of this kind of training. And crosscultural training is a more efficient way, because it can help managers to enhance their cultural sensitivity and adaptability. So it is the effective way to improve the efficiency of cross-culture management.

In addition, increase the proportion of cross-cultural management researchers in management team is a wonderful way.

With the development of Chinese higher education, student management will gradually develop into a subject. This requires the staff to get in-depth study of educational management, become a professional "researchers" on the basic theory and the law of development. As Wang Jun says, if you want to become an expert in student management, you should be a "researchers" instead of an actor.

Currently the degree of specialization and Scholaroriented of college student managers is low. This undoubtedly will be the main obstacles of specialization and Scholar-oriented. Therefore, increasing the proportion of researchers in students' management team and creating appropriate conditions for the researchers are the essential ways of the long-term development of college student management.

\section{Conclusions}

First of all, flatten the student management structure. Organizational structure includes the systematic arrangement of the staff, the demanding jobs, the needed technology, and information. And it is the basic premise to target fulfilment of student management effectively. From a histological point of view, the best organizational structure is the structure that suits your organization's specific criteria best. So the best structure is the one in line with the real specific condition of school and related to its characteristics.

Foreign students are deeply affected by Western culture which emphasizes the efficiency and effectiveness. This belief expresses a simple, refined, economical, efficient value. And the structures can be adjusted according to the changes. Therefore, a flat organization structure adjustment and reform is an important step in cross-culture management of students in colleges and universities. Then set up a professional Management Department is a good choice. Set up a professional Management Department in colleges and universities for cultural studies of students' background, and strengthen closely cooperation between Student Affairs and academy. So as my perception., in order to improve different cultural students' connection and understanding in Ethnic Chinese Schools, students' affairs sectors can often invite the experts to hold seminars in order to encourages managers and students from different cultures to stay together for better understanding. This is a win-win cooperation for students Affairs and academic affairs. Through regular communications, managers can share research results with students and enhance students' abilities to cross-cultural understanding.

\section{References}

[1] Chen Xiaoping. Cross-cultural Management. Beijing: Tsinghua Publishing House. 2005.

[2] Dong Guangqian. Synergy and Integration of College Cross-cultural Management. Journal of Northwest Normal University (Social Sciences). 2007.11

[3] Geert Hofstede. Cultures Consequences: Comparing values, behaviors, institutions, and organizations across nations.-2nd ed. Sage Publications, International Educational and Professional Publisher. 2001.

[4] Hong Haixing. Research on Cross-cultural Management of International Education Cooperation. Journal of Inner Mongolia Normal University (Education Science). 2012.1

[5] Hu Jun. The Theory and Practice of Cross-cultural education mode. Future and Development. 2009(5) 
[6] Su Guoxun. Globalization: Cultural Conflicts and Symbiosis. Social Sciences Academic Press. 2006.7.1

[7] Wang Suchun. An Elementary Research of Crosscultural Management of Foreign Students based on cultural differences. Mordent Management Science. 2010(12)

[8] Wang Jun. New Perspective of Professional Development of Higher Education. Advanced
Educational Research in Heilongjiang Province. 2007(8)

[9] Yao Ling. Cross-cultural Management of Higher Education. Advanced Educational Research in Heilongjiang Province. 2009.(9)

[10] Zhang Yutang. Cross-cultural Management in School. Journal of the Chinese Scholar of Education. 2002(4) 